\title{
STRATEGI PEMASARAN TAUCO CAP BIRUANG DI KABUPATEN CIANJUR
}

\author{
Zumi Saidah, Kuswarini Kusno, dan Eliana Wulandari \\ Staf Pengajar di Jurusan Sosial Ekonomi Pertanian, Fakultas Pertanian \\ Universitas Padjadjaran Bandung, Indonesia \\ e-mail : z_saidah@yahoo.com
}

\begin{abstract}
ABSTRAK. Saat ini, produksi tauco Cianjur kini semakin menyusut, seiring dengan berkurangnya jumlah pengusaha yang menggeluti usaha pembuatan makanan khas Cianjur ini. Melihat hal ini maka, perlu dicarikan solusi bagi para pengusaha tauco Cianjur agar mereka tetap dapat mempertahankan usahanya. Penelitian ini bertujuan untuk (1) mengetahui kendala-kendala internal dan eksternal perusahaan dalam memasarkan tauco Cap Biruang; (2) merekomendasikan strategi pemasaran yang lebih baik untuk meningkatkan dan mengembangan pemasaran tauco Cap Biruang. Penelitian ini dilakukan di perusahaan tauco Cap Biruang, Desa Pamayonan Kecamatan Cianjur Kota, Kabupaten Cianjur. Penelitian ini menggunakan metode studi kasus yang memusatkan perhatian pada suatu kasus perkembangan pemasaran tauco Cap Biruang di Kaupaten Cianjur secara intensif dan rinci dengan mengutamakan teknik pengumpulan datanya melalui observasi dan wawancara langsung. Pengolahan data dan informasi menggunakan analisis deskriptif dan analisis SWOT. Berdasarkan hasil analisis faktor internal dan eskternal yang telah dilakukan pada perusahaan tauco cap Biruang, maka dapat diketahui bahwa secara umum perusahaan tauco cap Biruang masih belum memanfaatkan secara maksimal kekuatan dan peluang yang ada untuk meminimalisir kelemahan dan ancaman. Hal ini dapat dibuktikan berdasarkan hasil perhitungan IFE dan EFE yang hanya mencapai skor 2.52 dan 2.40 yang apabila dilihat pada matriks Internal-Eksternal (IE) berada pada kolom V. Hal ini berarti pihak perusahaan tauco cap Biruang masih pada tahap sedang (rata-rata) yang baru mampu mencapai tahap strategi pemeliharaan, pertahankan (hold and maintain) melalui penetrasi pasar dan pengembangan produk. Strategi yang dapat diterapkan pada posisi ini adalah strategi penetrasi pasar dan pegembangan produk, dengan cara memperluas segmen pasar. Selain itu berdasarkan dari hasil analisa SWOT maka di dapatkan beberapa alternatif strategi diantaranya: meningkatkan kapasitas produksi agar dapat memenuhi permintaan pasar terutama pada saat-saat tertentu, memperluas area pemasaran, perlunya menjalin kemitraan dengan lembaga maupun pihak lainnya guna mengatasi ancaman dan meraih peluang yang ada. Selain itu juga perlu dilakukan perbaikan pencatatan keuangan mengingat selama ini pencatatan yang dilakukan oleh industri tauco cap Biruang hanya sebatas pencatatan sederhana tanpa ada perhitungan laba/rugi.
\end{abstract}

Kata Kunci : Strategi Pemasaran, Matriks IFE, Matriks EFE, Tauco Cap Biruang 
Strategi Pemasaran Tauco Cap Biruang di Kabupaten Cianjur

(Zumi Saidah, Kuswarini Kusno, dan Eliana Wulandari)

\title{
MARKETING STRATEGY OF BRAND TAUCHO BIRUANG IN CIANJUR DISTRICT
}

\begin{abstract}
Production of Cianjur tauco was decreasing with a reduced number of entrepreneurs who wrestle typical food-making business in Cianjur. They need a solutions for entrepreneurs tauco Cianjur so they can maintain their business. The aims of this research were to identify internal and external environment and industry tauco Biruang $d$ to recommend the best marketing strategy for business development. This research was conducted at the Industrial tauco Biruang, Cianjur District especially in the Pamayonan Village. This Reseach is a case study with survey research techniques. Data and information were processed by using descriptive and SWOT analysis. Based on the analysis of internal and external factors that have been done on the tauco Biruang, it can be seen that in general the industry is still not used the most of strengths and opportunities exist to minimize weaknesses and threats. This can be proved based on the calculations IFE and EFE which only reached a score of 2:52 and 2:40, which, if seen in the matrix of Internal-External (IE) is in column V. This means the Biruang industry is still in the stage of being (on average) are only able to reach the stage of maintenance strategies, sustain (hold and maintain) through market penetration and product development. The strategy can be applied for market penetration and product development, by expanding market segment. In addition, based on the results of the SWOT analysis is getting some alternative strategies including: increasing production capacity to develop market demand, especially at certain times, expanding areas of marketing, establish partnerships with institutions and other parties in order to overcome the threats and opportunities that exist . Biruang industry was needs a revision of financial records to remember during this recording conducted by industry tauco Biruang only a simple record without any calculation of profit / loss
\end{abstract}

Keywords : Marketing Strategy, EFE Matrix, IFE Matrix, Tauco Biruang

\section{PENDAHULUAN}

Dalam rangka pengembangan produksi pangan, pemerintah mengeluarkan kebijakan pertanian berupa program diversifikasi berupa tanaman sekunder dengan lebih memprioritaskan pada tanaman kedelai. Berbagai alternatif potensi untuk meningkatkan nilai tambah kedelai banyak dilakukan termasuk produk sampingannya melalui pemanfaatan teknologi pasca panen. Kedelai dapat diolah menjadi berbagai macam produk pangan, farmasi (obat-obatan), aplikasi dalam bidang teknik (industri) dan pakan ternak.

Salah satu hasil olahan kedelai yang sampai saat ini masih diproduksi dibeberapa daerah tauco yang berasal dari daerah Cianjur. Dalam perkembangannya, tauco di Kabupaten Cianjur banyak di usahakan dalam skala 
Usaha Mikro, Kecil dan Menengah (UMKM). Dimana pengusahaan tauco dalam skala usaha rumah tangga merupakan kelompok usaha yang memiliki jumlah paling besar dan paling banyak muncul pada saat musim-musim tertentu seperti hari libur dan hari raya (Disperindag Cianjur, 2010).

Salah satu perusahaan tauco di Cianjur tertua yang sampe saat ini masih bertahan memproduksi dan mengembangkan tauco di Cianjur adalah tauco Cap Biruang. Sejak perusahaan tauco ini berdiri sampai sekarang, hasil produksinya dijual di toko manisan dan oleh-oleh khas Cianjur yang tersebar di wilayah Cianjur. Target pasar tauco Cap Biruang ini adalah para pendatang (konsumen luar Cianjur) yang sekedar singgah di toko manisan dan oleh-oleh Cianjur.

Seiring perkembangan wilayah dan waktu, persaingan terhadap produk ini mulai mengalami penurunan. Menurunnya produksi tauco Cianjur ini terjadi seiring dengan berkurangnya jumlah pengusaha yang menggeluti usaha pembuatan makanan khas Cianjur ini. Banyak pengusaha tauco yang gulung tikar atau pindah ke usaha lain. Hal ini dikarenakan sepinya konsumen yang membeli oleh-oleh khas Cianjur sehingga menurunkan omset penjualan para pengusaha tauco ini. Sepinya konsumen diakibatkan karena dibukanya jalur tol Cipularang yang menghubungkan Jakarta dan Bandung sehingga konsumen yang biasanya melalui jalur ini beralih ke jalan tol Cipularang (Widayanti, 2006).

Perlu diupayakan solusi bagi para pengusaha tauco Cianjur agar mereka tetap dapat mempertahankan usahanya serta dapat bersaing di era pasar global dalam memenuhi kebutuhan konsumen. Salah satu solusi yang perlu dilakukan pengusaha tauco Cap Biruang adalah mengembangkan segmentasi pasar untuk produk tauco yang dihasilkan serta perlunya kecermatan pengusaha tauco untuk melihat peluang-peluang keberhasilan dan peka terhadap kemungkinankemungkinan kegagalan. Salah satu upaya yang dapat dilakukan adalah dengan mengidentifikasi faktor internal maupun faktor eksternal perusahaan (David, 2006). Pertimbangan kedua faktor tersebut diharapkan dapat membawa keberhasilan dalam memasarkan tauco cap Biruang.

Selain pertimbangan dari kedua faktor di atas, perusahaan tauco cap Biruang juga dituntut untuk mampu meningkatkan pelayanan kepada para konsumennya dengan cara memenuhi permintaan akan kualitas dan kuantitas produk tauco yang sesuai dengan keinginan konsumen. Selain itu, pemasaran tauco seharusnya tidak hanya terbatas pada toko oleh-oleh khas Cianjur namun dapat dikembangkan dengan memasuki pasar baru seperti pasar tradisonal, rumah makan, dan lain sebagainya.

Berdasarkan uraian di atas maka perlu dijabarkan strategi yang lebih baik agar perusahaan tauco Cap Biruang dapat mengembangkan pasar tauconya dan dapat bersaing dengan produk tauco sejenis.

Adapun tujuan yang ingin dicapai dalam penelitian ini adalah untuk mengetahui dan menguraikan:

1. Mengetahui kendala-kendala internal dan eksternal perusahaan dalam memasarkan tauco Cap Biruang 
2. Merekomendasikan strategi pemasaran yang lebih baik bagi perusahaan untuk meningkatkan dan mengembangkan pemasaran tauco Cap Biruang

\section{METODE}

Metode yang diterapkan dalam pengumpulan data pada penelitian ini adalah dengan cara pengamatan langsung (observasi) dan wawancara langsung dengan pihak-pihak yang terkait dengan pencarian strategi bagi pemasaran tauco Cap Biruang. Penelitian ini dilakukan di perusahaan tauco Cap Biruang, Jalan Slamet Riyadi No. 28 B Desa Pamayonan Kecamatan Cianjur Kota, Kabupaten Cianjur. Pemilihan perusahaan tauco Cap Biruang dilakukan dengan sengaja (purposive) dengan pertimbangan perusahaan ini merupakan salah satu perusahaan tauco yang sudah lama berdiri (50 tahun) di Kabupaten Cianjur dan masih bisa bertahan hingga saat ini.

\section{HASIL DAN PEMBAHASAN \\ Perkembangan Tauco dan Tauco Cap Biruang di Cianjur}

Kota Cianjur merupakan salah satu kota yang terkenal dengan produk tauco sebagai salah satu oleh-oleh khas dari kota ini. Salah satu perusahaan yang cukup lama mengelola usaha tauco di Kabupaten Cianjur adalah tauco Cap Biruang. Perusahaan Tauco Cap Biruang atau yang lebih dikenal dengan nama Tauco $\mathrm{H}$. Mochammad Sholeh, merupakan perusahaan tauco milik perseorangan yang didirikan pada tahun 1960 oleh Bapak H. Mochammad Sholeh di Santiong (daerah Cikaret, Cianjur).

Perusahaan tauco Cap Biruang mencoba mengikuti kesuksesan yang diperoleh perusahaan tauco Cap Meong. Sejak saat itu, muncul perusahaan tauco lainnya dan dari beberapa periode perkembangan hingga saat ini hanya tinggal enam (6) merek tauco lokal yang cukup dikenal di Cianjur diantaranya tauco Cap Meong, tauco Cap Biruang, tauco Cap Djajuli Putra, tauco Cap Badak, tauco Cap Harimau, dan tauco Cap Macan Tutul.

Pada tahun 1964, H. Mochammad Soleh mempercayakan dan mengalihkan kepemimpinan perusahaan tauco Cap Biruang kepada anaknya H. E. Rosadi. Pada masa kepemimpinan bapak Rosadi, perusahaaan tauco Cap Biruang mulai memperlihatkan perkembangan dan peningkatan terutama dalam hal peningkatan mutu produk tauco dengan mendaftarkan produk tauco Cap Biruang pada Departemen Kesehatan RI dengan Nomor Dep. Kes. RI. No. MD. 104527.

Saat ini perusahaan tauco Cap Biruang telah memasuki generasi ketiga, dimana pengelolaan kepemimpinannya diserahan kepada anaknya ibu Tini Supartini yang dibantu oleh bapak Johan Arifin. Pada masa kepemimpinan ibu Tini dan pak Johan, perusahaan tauco Cap Biruang terdaftar di Departemen Perindustrian dan Perdagangan dengan Surat Ijin Usaha Perdagangan (SIUP) No. 53/0355/PK/B/VII/2002 yang dikeluarkan pada tanggal 2 Juli 2002. Pada tahun 2006 perusahaan tauco Cap Biruang mendapatkan label halal dari Majelis Ulama Indonesia (MUI). 


\section{Pemasaran yang dilakukan Tauco Cap Biruang}

Perusahaan tauco Cap Biruang merupakan perusahaan yang bergerak di bidang pengolahan kedelai dimana produk tauco yang terkenal dengan baunya yang wangi serta rasa dan kelezatannya yang manis dan gurih. Tauco yang dihasilkan oleh perusahaan tauco Cap Biruang terdiri dari dua macam jenis tauco yaitu tauco kering dan tauco basah (cair).

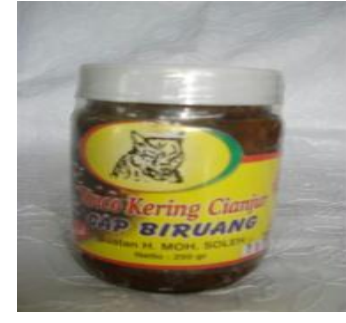

a.

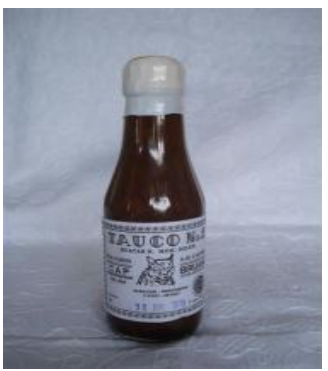

(c)

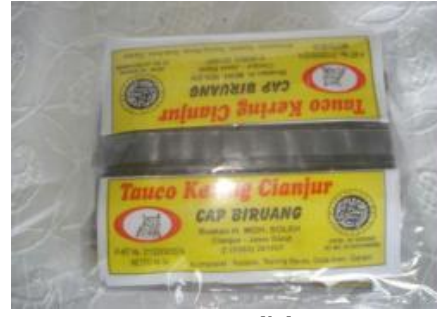

(b)

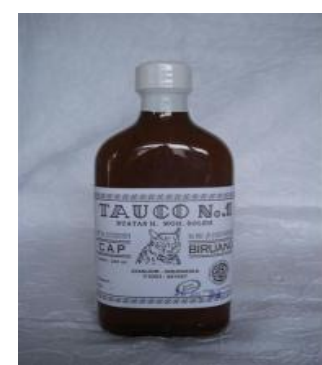

(d)

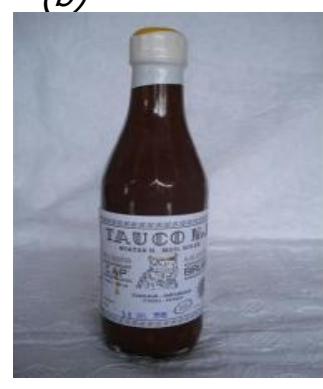

Gambar 1 . Bentuk Kemasan, Jenis Tauco, Beserta Ukuran Tauco Cap Biruang : (a) Tauco Cair Ukuran 250 gram; (b) Tauco Kering Isi 4 sachet @ 65 gram; (c) Tauco Cair Ukuran 240 ml; (d) Tauco Cair Ukuran 350 ml; dan Tauco Cair Ukuran $475 \mathrm{ml}$.

Perbedaan diantara keduanya adalah tauco basah berbentuk pasta dan dikemas dalam botol, sedangkan tauco kering dikemas dalam plastik. Berdasarkan kekuatan (ketahanan produk), maka terdapat perbedaan tauco cair dapat bertahan dipasaran selama dua sampai dengan empat bulan, sedangkan untuk tauco kering dapat bertahan selama empat sampai dengan enam bulan. Ketahanan dari produk tauco ini juga berfluktuasi yang diperkirakan diakibatkan oleh penanganan pada saat pemasukan produk ke dalam kemasan yang masih bersifat manual (tradisional).

Pemberian label yang dicetak sendiri oleh pihak perusahaan. Label yang digunakan pada tauco cair bergambar kepala beruang dengan warna hitam putih sedangkan pada tauco kering label yang digunakan adalah label warna kuning 
Berikut ini adalah beberapa bentuk kemasan, jenis tauco, serta berbagai ukuran kemasan tauco yang pernah dan diproduksi di perusahaan tauco cap Biruang.

Kegiatan penjualan tauco Cap Biruang tidak selalu berjalan baik. Sistem pemasaran yang dimiliki oleh tauco Cap Biruang masih sangat terbatas dan cendrung pasif karena hanya mengandalkan pelanggan yang sekaligus berperan sebagai pengecer. Keberadaan tauco cap Biruang ini belum begitu dikenal sama masyarakat Cianjur sendiri, karena untuk pemasarannya lebih banyak diarahkan pada pemasaran di pusat oleh-oleh khas Cianjur yang pembelinya biasanya berasal dari luar kota Cianjur.

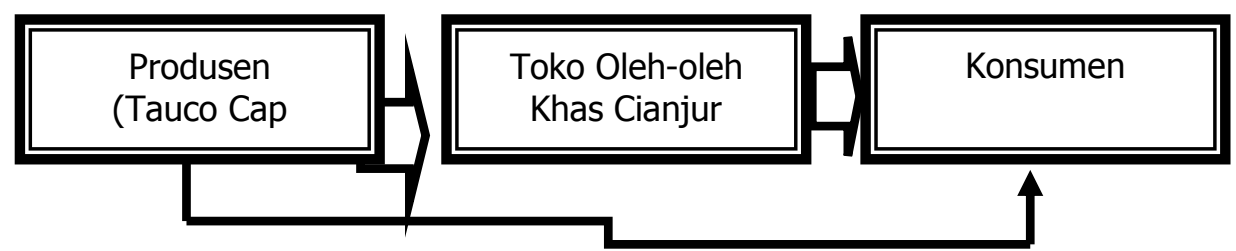

Gambar 2. Jalur Tataniaga Tauco Cap Biruang

Dalam menjalankan usahanya tauco Cap Biruang belum memiliki rancangan strategi pemasaran yang harus di jalankan. Hal ini disebabkan karena tidak adanya perencanaan pemasaran. Menurut Kotler (2002), dalam proses pemasaran diperlukan suatu perencanaan yang merupakan salah satu proses manajemen pemasaran yang berkaitan dengan perencanaan strategi perusahaan untuk mencapai tujuan yang telah ditentukan. Selain itu keterbatasan tenaga pemasaran pada perusahaan tauco cap Biruang yang melakukan semua fungsi pemasaran seperti menjual dan mendistribusikan hingga pencarian pelanggan baru, membuat kegiatan pemasaran yang di jalankan oleh industri tauco Cap Biruang menjadi tidak efektif dan tidak efisien.

Gambaran jalur tataniaga yang selama ini dilakukan oleh tauco cap Biruang terlihat bahwa industri tauco cap Biruang belum memanfaatkan secara maksimal semua segmen pasar yang ada. Bila dilihat secara ringkas Segmenting, Targeting dan Positioning (STP) yang telah dilakukan oleh produk tauco cap Biruang, maka terlihat bahwa tauco cap Biruang masih mengandalkan penjualan produknya dari toko manisan dan oleh-oleh khas Cianjur padahal tidak tertutup kemungkinan apabila perusahaan tauco cap Biruang mau mencoba memasuki pasar lokal (pasar tradisonal maupun melalui pedagang pengecer) untuk daerah Cianjur sendiri tidak tertutup kemungkinan terdapat konsumen yang nantinya akan mempengaruhi permintaan terhadap tauco cap Biruang yang ditawarkan.

Tidak ada promosi khusus yang dilakukan dalam memasarkan produk tauco ini. Selama ini Pemda daerah Cianjur sudah memberikan bimbingan berupa pelatihan dan penyuluhan kepada para pengusaha tauco. Salah satu upaya yang dilakukan untuk mengembangkan pemasaran produk dengan menambahkan jumlah outlet-outlet yang memasarkan produk khusus khas Cianjur. 
Tabel 1. Data Penjualan Tauco Cap Biruang Tahun 2008

\begin{tabular}{lcccc}
\hline \multirow{2}{*}{ Bulan } & \multicolumn{4}{c}{ Jumlah Penjualan Tauco } \\
\cline { 2 - 5 } & \multicolumn{2}{c}{ Tauco Cair (Botol) } & Tauco Kering (Bungkus) \\
\cline { 2 - 5 } & $\mathbf{3 5 0} \mathbf{~ m l}$ & $\mathbf{2 4 0} \mathbf{~ m l}$ & $\mathbf{2 6 0} \mathbf{~ g r}$ & $\mathbf{2 5 0} \mathbf{~ g r}$ \\
\hline Januari & 6300 & 4000 & 3000 & 2750 \\
\hline Februari & 1800 & 3650 & 1200 & 1000 \\
\hline Maret & 2850 & 2800 & 1500 & 2500 \\
\hline April & 2200 & 2800 & 2250 & 1800 \\
\hline Mei & 4300 & 2800 & 3000 & 1800 \\
\hline Juni & 4250 & 3250 & 2500 & 2500 \\
\hline Juli & 4400 & 4100 & 3750 & 2750 \\
\hline Agustus & 3000 & 2700 & 3000 & 2000 \\
\hline September & 3700 & 2700 & 3000 & 2300 \\
\hline Oktober & 3700 & 3500 & 3000 & 1860 \\
\hline November & 5500 & 4650 & 5000 & 3700 \\
\hline Desember & 5500 & 4000 & 4500 & 3500 \\
\hline Sumber: Perush
\end{tabular}

Sumber: Perusahaan Tauco Cap Biruang 2008

Tabel 2. Perbandingan Harga Tauco Cap Biruang dengan Beberapa Merk Tauco lainnya

\begin{tabular}{|c|c|c|c|c|}
\hline Merk Produk & $\begin{array}{l}\text { Jenis } \\
\text { Tauco }\end{array}$ & Ukuran & Satuan & $\begin{array}{c}\text { Harga } \\
(\mathbf{R p})\end{array}$ \\
\hline \multirow{2}{*}{$\begin{array}{l}\text { Tauco Cap Meong } \\
\text { (Ny. Tasman) }\end{array}$} & Cair & 350 & $\mathrm{ml}$ & 12.000 \\
\hline & Cair & 240 & $\mathrm{ml}$ & 8000 \\
\hline \multirow{6}{*}{$\begin{array}{l}\text { Tauco Cap Biruang } \\
\text { (H. Moch. Sholeh) }\end{array}$} & Cair & 350 & $\mathrm{ml}$ & 6000 \\
\hline & Cair & 240 & $\mathrm{ml}$ & 5000 \\
\hline & Cair & 200 & $\mathrm{ml}$ & 4000 \\
\hline & Kering & 260 & gram & 5000 \\
\hline & Kering & 250 & gram & 7000 \\
\hline & Kering & 100 & gram & 1500 \\
\hline Tauco Cap Djajuli & Kering & 350 & gram & 5000 \\
\hline $\begin{array}{l}\text { Putra } \\
\text { (H.M. Dajjuli Putra) }\end{array}$ & Kering & 240 & gram & 4000 \\
\hline \multicolumn{5}{|c|}{ Sumber : Data Primer (2010) } \\
\hline
\end{tabular}


Putra, Tauco Cap Macan, tauco Cap Badak serta tauco-tauco lainnya semakin memperketat pemasaran dan persaingan produk tauco yang ditawarkan. Selain perusahaan-perusahaan tauco tersebut terkadang juga sering muncul para pembuat tauco dadakan yang memanfaatkan peluang permintaan yang terkadang cukup tinggi di waktu-waktu tertentu.

Seiring dengan beroperasinya jalan tol Cikampek-Purwakarta-Padalarang (Cipularang), Januari 2004, bisnis tauco mulai meredup. Dengan dibangunnya jalan tol Cikampek membuat tidak banyak lagi wisatawan lokal yang melintasi Cianjur bila hendak ke Bandung atau Jakarta. Hal ini membuat omzet penjualan tauco semakin susut (Widayanti, 2006).

\section{Analisis Matriks IFE, EFE dan IE}

Faktor-faktor yang dianalisis dengan matriks ini adalah faktor-faktor strategis internal dan eksternal perusahaan. Matriks Internal Factor Evaluation (IFE) dan External Factor Evaluation (EFE) merupakan teknik yang digunakan pada tahap masukan (The Input Stage) dari kerangka kerja perumusan startegi. Matriks IFE dan EFE beserta dengan penyataan misi yang jelas menyediakan informasi dasar yang diperlukan untuk merumuskan strategi secara sukses dengan syarat teknik ini disertai penilaian intuitif yang baik dalam menetapkan pembobotan dan penilaian yang tepat (Singh, 2010).

Matriks faktor evaluasi internal merupakan alat manajemen strategis untuk mengevaluasi kekuatan dan kelemahan dalam bidang fungsional bisnis. Matriks IFE bersama-sama dengan matriks EFE adalah alat formulasi strategi yang dapat digunakan untuk mengevaluasi bagaimana kinerja sebuah perusahaan terutama kekuatan dan kelemahan internal perusahaan diidentifikasi (Ommani, 2011).

Hasil dari matriks IFE tauco cap Biruang pada tabel di bawah ini terlihat bahwa penilaian responden terhadap faktor-faktor kunci internal perusahaan, didapatkan total skor rata-rata IFE sebesar 2,52. Hal ini berarti bahwa posisi strategi perusahaan tauco Cap Biruang berada pada posisi sedang (rata-rata) dalam memanfaatkan kekuatan yang dimiliki untuk menghadapi kelemahan internal perusahaan.

Pada tabel tersebut dapat dikatakan bahwa perusahaan tauco cap Biruang belum secara maksimal memanfaatkan kekuatan yang dimiliki untuk menutupi kelemahan yang ada. Sebagai contoh bahwa produk tauco cap Biruang cukup di kenal di kalangan para pembeli atau produsen yang datang dari luar Cianjur maupun kuatnya hubungan baik antara perusahaan tauco cap Biruang dengan pemasok bahan baku seharusnya dapat menutupi kekurangan atau kelemahannya dalam memenuhi permintaan akan produk tauco. 
Tabel 3. Rata-rata Matriks IFE Tauco Cap Biruang

\begin{tabular}{|c|c|c|c|}
\hline Faktor Internal & Bobot & Rating & Bobot Skor \\
\hline \multicolumn{4}{|l|}{ Kekuatan : } \\
\hline $\begin{array}{l}\text { A. Kualitas \& mutu produk sudah di } \\
\text { kenal baik }\end{array}$ & 0,07 & 3,67 & 0,26 \\
\hline B. Tenaga kerja terampil & 0,07 & 3,67 & 0,25 \\
\hline C. Akses Bahan baku yang cukup kuat & 0,07 & 3,67 & 0,26 \\
\hline D. Motivasi yang tinggi & 0,09 & 3,00 & 0,24 \\
\hline Paket teknologi yang tersedia & 0,08 & 3,33 & 0,23 \\
\hline \multicolumn{4}{|l|}{ Kelemahan : } \\
\hline F. Kemampuan produksi rendah & 0,07 & 2,33 & 0,16 \\
\hline G. Keterbatasan modal usaha & 0,07 & 2,33 & 0,16 \\
\hline Kurangnya mitra usaha & 0,07 & 2,00 & 0,13 \\
\hline Harga jual produk kurang bersaing & 0,07 & 2,00 & 0,14 \\
\hline Kurangnya dukungan pemerintah & 0,07 & 1,67 & 0,12 \\
\hline $\begin{array}{l}\text { K. Kegiatan Promosi Penjualan kurang } \\
\text { efektif }\end{array}$ & 0,07 & 2,00 & 0,13 \\
\hline $\begin{array}{l}\text { L. Lokasi \& tempat produksi kurang } \\
\text { strategis }\end{array}$ & 0,07 & 1,67 & 0,12 \\
\hline $\begin{array}{lll}\text { M. } & \begin{array}{l}\text { Pengelolaan manajemen usaha } \\
\text { sederhana }\end{array} \\
\end{array}$ & 0,08 & 2,00 & 0,15 \\
\hline $\begin{array}{lll}\text { N. } & \begin{array}{l}\text { Pencatatan keuangan } \\
\text { sistematis }\end{array} \\
\end{array}$ & 0,08 & 2,00 & 0,15 \\
\hline Total & 1,00 & & 2,52 \\
\hline
\end{tabular}

Matriks EFE merupakan alat strategis manajemen yang sering digunakan untuk penilaian kondisi bisnis saat ini. Matriks EFE adalah alat yang baik untuk memvisualisasikan dan memprioritaskan peluang dan ancaman yang dihadapi perusahaan. Berdasarkan hasil pada analisis EFE, diperoleh jumlah skor rata-rata untuk faktor kunci eksternal sebesar 2,40 yang artinya kemampuan perusahaan untuk memanfaatkan peluang yang ada dan mengatasi ancaman-ancaman yang dihadapi perusahaan berada pada kondisi sedang atau rata-rata. Padahal menurut (David, 2006), peluang merupakan salah satu faktor eksternal yang bernilai positif yang dapat dimanfaatkan perusahaan untuk mengembangkan produknya. Hal ini juga menunjukkan bahwa perusahaan Tauco cap Biruang belum memanfaatkan secara maksimal peluang-peluang yang ada untuk menghindari ancaman.

Berdasarkan tabel berikut dapat dilihat bahwa perusahaan tauco cap Biruang masih lemah dalam menangkap peluang yang ada di antaranya untuk pengembangan area pemasaran baru yang tidak hanya fokus pada daerah penjualan di pusat oleh-oleh Cianjur. Tapi juga seharusnya mampu memanfaatkan peluang pasar dengan memasuki pasar tradisional, dan rumah-rumah makan 
ataupun hotel dan restoran. Hal ini dilakukan untuk memperluas pangsa pasar sehingga produk tauco cap Biruang tidak hanya di kenal oleh para pendatang dari luar tapi juga di kenal oleh masyarakat Cianjur.

Tabel 4. Matriks EFE Tauco Cap Biruang

\begin{tabular}{|c|c|c|c|}
\hline Faktor Eksternal & Bobot & Rating & Bobot Skor \\
\hline \multicolumn{4}{|l|}{ Peluang : } \\
\hline A. Perubahan Pola konsumsi masyarakat & 0,08 & 2,00 & 0,16 \\
\hline $\begin{array}{l}\text { B. Masih banyaknya pangsa pasar yang } \\
\text { belum terjangkau }\end{array}$ & 0,07 & 3,00 & 0,20 \\
\hline C. Dukungan pemerintah terhadap UMKM & 0,07 & 3,33 & 0,23 \\
\hline D. Pelanggan yang loyal & 0,08 & 2,67 & 0,20 \\
\hline E. Teknologi yang semakin berkembang & 0,06 & 3,00 & 0,19 \\
\hline $\begin{array}{lll}\text { F. } & \begin{array}{l}\text { Kebiasaan mengkonsumsi masakan } \\
\text { dengan bumbu tauco }\end{array} \\
\end{array}$ & 0,06 & 3.67 & 0,24 \\
\hline G. $\quad$ Perkembangan retailer (pengecer) & 0,08 & 3,00 & 0,25 \\
\hline \multicolumn{4}{|l|}{ Ancaman : } \\
\hline H. $\quad$ Biaya input yang cukup tinggi & 0,08 & 2,33 & 0,18 \\
\hline I. Persaingan dengan usaha sejenis & 0,08 & 2,33 & 0,18 \\
\hline J. Akses modal terbatas & 0,07 & 1,67 & 0,12 \\
\hline K. Adanya produk subtitusi & 0,07 & 2,00 & 0,14 \\
\hline Masuknya produk baru yang lebih unggul & 0,07 & 1,67 & 0,12 \\
\hline M. $\quad$ Inovasi produk dari pesaing & 0,07 & 1,67 & 0,11 \\
\hline $\begin{array}{l}\text { N. Kondisi politik, ekonomi dan keamanan } \\
\text { yang tidak kondusif }\end{array}$ & 0,06 & 1,33 & 0,08 \\
\hline Total & & & 2,40 \\
\hline
\end{tabular}

Sumber : Data olahan

Manajemen strategis dianggap penting bagi perusahaan karena manajemen strategis mampu mengevaluasi faktor-faktor internal dan faktor eksternal dengan menggunakan matriks IFE dan matriks EFE guna mengantisipasi lingkungan perusahaan yang selalu berubah-ubah (Singh, 2010).

Pemetaan posisi perusahaan sangat penting bagi pemilihan alternatif strategi dalam menghadapi persaingan dan perubahan yang terjadi dalam usaha tauco cap Biruang. Dengan nilai matriks IFE sebesar 2,52 maka tauco cap Biruang memiliki faktor internal yang berada dalam kondisi yang sedang (rata-rata) dalam memanfaatkan faktor-faktor internal yang dimiliki perusahaan. Nilai matriks EFE sebesar 2,40 memperlihatkan respon yang diberikan perusahaan terhadap lingkungan eksternal tergolong sedang atau rata-rata.

Apabila masing-masing total skor dari faktor internal maupun eksternal dipetakan ke dalam matriks IE, maka posisi perusahaan saat ini berada pada sel 2 yang dapat dilihat pada gambar di bawah ini. Pada sel ini posisi perusahaan tauco 
Cap Biruang berada pada daerah tumbuh dan kembang (growth \& build) yang terdiri dari strategi intensif atau integrasi. Pada posisi ini perusahaan tauco cap Biruang dituntut agar dapat meningkatkan kemampuan perusahaan seiring perkembangan usaha dengan melihat faktor-faktor lingkungan internal dan eksternal yang terjadi di perusahaan. Pada sel V daerah tumbuh kembang terdapat beberapa strategi yang dapat dijalankan yaitu strategi pelihara, pertahankan ( hold and maintain) melalui penetrasi pasar dan pengembangan produk.

Strategi yang dihasilkan pada matriks IE hanya menghasilkan alternatif strategi secara umum tanpa adanya implementasi strategi yang lebih teknis pada tingkat perusahaan oleh karena itu matriks IE dilengkapi oleh matriks SWOT yang berupa langkah-langkah konkrit yang sebaiknya dilakukan oleh perusahaan.

\section{Analisis Matriks SWOT (Strengths, Weaknesses, Opportunities, Threats)}

Setelah dilakukan perhitungan dalam matriks IFE dan EFE, kedua matriks tersebut disatukan dalam matriks IE yang kemudian disajikan dalam susunan yang baik dan rapi untuk di olah dengan metode matriks SWOT yang terdiri dari kekuatan (Strength), kelemahan (Weakness), peluang (Oportunity) dan ancaman (Threat) (David, 2006). Metode Analisis SWOT digunakan untuk menentukan faktor-faktor yang dapat membantu perusahaan dalam mencapai tujuannya, dan faktor-faktor hambatan yang harus diatasi atau diminimalkan untuk mencapai hasil yang diinginkan (Singh, 2010).

Berdasarkan empat macam kelompok alternatif strategi yang dapat ditempuh dalam matriks SWOT maka perusahaan tauco cap Biruang terdapat beberapa alternatif strategi yang dapat direkomendasikan antara lain meningkatkan kapasitas produksi agar dapat memenuhi permintaan pasar dengan cara menambah kuantitas tauco yang dihasikan baik berupa tauco kering maupun tauco basah agar dapat memenuhi permintaan pasar.

Strategi lainnya adalah dengan memperluas area pemasaran dengan memasuki segmen pasar baru seperti memasuki pasar tradisonal, maupun rumahrumah makan. Mempertahankan dan meningkatkan kualitas produk juga merupakan strategi penting lainnya yang harus diperhatikan perusahaan agar ketahanan dan kesterilan produk terjaga dengan baik sampai di tangan konsumen. Selain itu, untuk menarik minat konsumen tauco Cap Biruang perlu menjalin kemitraan dengan pihak maupun lembaga lainnya. Hafsah (1999) mengatakan bahwa kemitraan adalah suatu strategi bisnis yang dilakukan oleh dua pihak atau lebih dalam jangka waktu tertentu untuk meraih keuntungan bersama dengan prinsip saling membutuhkan dan saling membesarkan .

Perusahaan tauco Cap Biruang sebaiknya lebih aktif mengikuti event-event yang diadakan baik oleh pihak pemerintah maupun swasta dengan memanfaatkan momen tersebut sebagai salah satu media untuk melakukan promosi dengan biaya yang cukup murah, melakukan perbaikan terhadap sistem pencatatan administrasi dan keuangan, menetapkan strategi harga yang lebih baik, memperbaiki desain produk agar terlihat berbeda dari pesaingnya berusaha mencari tahu keinginan 
Strategi Pemasaran Tauco Cap Biruang di Kabupaten Cianjur (Zumi Saidah, Kuswarini Kusno, dan Eliana Wulandari)

konsumen akan produk tauco yang ada di pasaran dan agresif dalam mencari informasi dan bantuan dana untuk modal usaha serta berusaha membuat berbagai inovasi produk yang berbahan baku kedelai.

Tabel 6. Matriks SWOT Tauco Cap Biruang

\begin{tabular}{|c|c|c|}
\hline & Kekuatan (Streghts) & Kelemahan (Weakness) \\
\hline $\begin{array}{l}\text { Faktor Eksternal } \\
\text { (EFE) }\end{array}$ & $\begin{array}{l}\text { 1. Kualitas \& mutu produk } \\
\text { sudah di kenal baik } \\
\text { 2. Tenaga kerja cukup } \\
\text { terampil } \\
\text { 3. Akses bahan baku yang } \\
\text { cukup kuat } \\
\text { 4. Motivasi yang tinggi } \\
\text { 5. Paket teknologi yang } \\
\text { tersedia }\end{array}$ & $\begin{array}{l}\text { 1. Kemampuan produksi } \\
\text { rendah } \\
\text { 2. Keterbatasan modal usaha } \\
\text { 3. Kurangnya mitra usaha } \\
\text { 4. Harga jual produk yang } \\
\text { kurang bersaing } \\
\text { 5. Kurangnya dukungan } \\
\text { pemerintah } \\
\text { 6. Kegiatan promosi penjualan } \\
\text { yang kurang efektif } \\
\text { 7. Lokasi \& tempat produksi } \\
\text { yang kurang efektif } \\
\text { 8. Pengelolaan manajemen } \\
\text { usaha sederhana } \\
\text { 9. Pencatatan keuangan tidak } \\
\text { sistematis }\end{array}$ \\
\hline Peluang (Opportunities) & Strategi S-O & Strategi W-O \\
\hline $\begin{array}{ll}\text { 1. } & \text { Perubahan pola konsumsi } \\
\text { masyarakat } \\
\text { 2. }\end{array}$ & $\begin{array}{l}\text { SO1. Meningkatkan } \\
\text { kapasitas produksi } \\
\text { agar dapat memenuhi } \\
\text { permintaan pasar } \\
\text { SO2. Memperluas area } \\
\text { pemasaran dengan } \\
\text { memasuki segmen } \\
\text { pasar baru } \\
\text { SO3. Mempertahankan dan } \\
\text { meningkatkan kualitas } \\
\text { SO4. Perlunya menjalin } \\
\text { kemitraan yang lebih } \\
\text { baik dengan lembaga } \\
\text { lainnya } \\
\text { SO5. Memberikan inovasi } \\
\text { pada produk tauco }\end{array}$ & $\begin{array}{l}\text { WO1. Mengikuti event-event } \\
\text { yang ada sebagai media } \\
\text { promosi. } \\
\text { WO2. Perlunya menjalin } \\
\text { kemitraan dan kerjasama } \\
\text { dengan pihak ataupun } \\
\text { lembaga lain untuk } \\
\text { mengisi peluang yang } \\
\text { ada. } \\
\text { WO3. } \\
\text { Memperbaiki pencatatan } \\
\text { (administrasi a } \\
\text { keuangan) agar dpt } \\
\text { mengetahui rugi/laba. }\end{array}$ \\
\hline Ancaman (Threats) & $\begin{array}{c}\text { Strategi S-T } \\
\end{array}$ & $\begin{array}{l}\text { Strategi W-T } \\
\end{array}$ \\
\hline $\begin{array}{ll}\text { 1. } & \text { Biaya input yang cukup tinggi } \\
\text { 2. Persaingan dengan usaha } \\
\text { sejenis } \\
\text { 3. Akses modal terbatas } \\
\text { 4. Adanya produk subtitusi } \\
\text { 5. Masuknya produk baru yang } \\
\text { lebih unggul } \\
\text { 6. Inovasi dari produk pesaing } \\
\text { 7. Kondisi politik, ekonomi dan } \\
\text { keamanan yang tidak } \\
\text { kondusif }\end{array}$ & $\begin{array}{l}\text { ST1. } \begin{array}{c}\text { Menetapkan strategi } \\
\text { harga yang lebih baik }\end{array} \\
\text { ST2. Mengajukan pinjaman } \\
\text { modal agar dapat } \\
\text { lebih memperlancar } \\
\text { usaha. } \\
\text { ST3. Memperbaiki desain } \\
\text { produk agar terlihat } \\
\text { berbeda dengan } \\
\text { produk pesaing }\end{array}$ & $\begin{array}{l}\text { WT1. Berusaha mencari tau } \\
\text { keinginan konsumen akan } \\
\text { produk tauco. } \\
\text { WT2. Agresif dalam mencari } \\
\text { informasi dan bantuan } \\
\text { dana usaha } \\
\text { WT3. Berusaha membuat } \\
\text { berbagai inovasi dari } \\
\text { bahan kedelai }\end{array}$ \\
\hline
\end{tabular}




\section{SIMPULAN}

Berdasarkan hasil analisis faktor internal dan eskternal yang telah dilakukan pada perusahaan tauco cap Biruang, maka dapat diketahui bahwa secara umum perusahaan tauco cap Biruang masih belum memanfaatkan secara maksimal kekuatan dan peluang yang ada untuk meminimalisir kelemahan dan anacaman. Hal ini dapat dibuktikan berdasarkan hasil perhitungan Internal Factor Evaluation (IFE) dan External Factor Evaluation (EFE) yang hanya mencapai skor 2,52 dan 2,40 yang apabila dilihat pada matriks Internal-External (IE) berada pada kolom V. Hal ini berarti pihak perusahaan tauco cap Biruang masih pada tahap sedang (ratarata) yang baru mampu mencapai tahap strategi pemeliharaan, pertahankan ( hold and maintain) melalui penetrasi pasar dan pengembangan produk. Strategi yang dapat diterapkan pada posisi ini adalah strategi penetrasi pasar dan pegembangan produk, dengan cara memperluas segmen pasar.

Selain itu berdasarkan dari hasil analisa SWOT maka di dapatkan beberapa alternatif strategi diantaranya: meningkatkan kapasitas produksi agar dapat memenuhi permintaan pasar terutama pada saat-saat tertentu, memperluas area pemasaran, perlunya menjalin kemitraan dengan lembaga maupun pihak lainnya guna mengatasi ancaman dan meraih peluang yang ada. Selain itu juga perlu dilakukan perbaikan pencatatan keuangan mengingat selama ini pencatatan yang dilakukan oleh perusahaan tauco cap Biruang hanya sebatas pencatatan sederhana tanpa ada perhitungan laba/rugi.

\section{UCAPAN TERIMA KASIH}

Penulis mengucapkan terima kasih kepada Lembaga Penelitin dan Pengabdian Masyarakat Universitas Padjadjaran atas bantuan dana DIPA Universitas Padjadjaran tahun anggaran 2010. Penulis juga mengucapkan rasa terima kasih pada pimpinan dan segenap karyawan yang ada di perusahaan tauco Cap Biruang yang selama ini telah banyak membantu penulis dalam mengumpulkan data dan informasi yang dibutuhkan.

\section{DAFTAR PUSTAKA}

David, Fred, R. 2006. Manajemen Strategies: Konsep. Versi Bahasa Indonseia. Edisi Ketujuh. PT Prenhallindo, Jakarta.

Disperindag Kab. Cianjur. 2010. Laporan Tahunan 2005-2010. Pemerintah Kabupaten Cianjur.

Kotler, Philip. 2002. Manajemen Pemasaran. Edisi Melinium, Jilid 2. Prenhallindo. Jakarta.

Hafsah, Muhammad Jafar. 1999. Kemitraan Usaha. Pustaka Sinar Harapan. Jakarta. 
Ommani, Ahmad Reza. 2011. Strengths, weakness, opportunity and threats (SWOT) analysis for farming system businesses management: Case of wheat farmers of Shadervan District, Shoushtar Township, Iran. African Journal of Business Management Vol.5 (22), pp. 9448-9454,30 September, 2011. Department of Agricultural Management, Shoushtar Branch, Islamic Azad University, Shoushtar, Iran.

Singh N (2010). SWOT Analysis - A Useful Tool For Community Vision A concept paper of central Himalayan village. Res., 2(9): 16-18.

Widayanti, Imas. 2006. Strategi Pengembangan Pasar Produk Tauco Khas Cinajur Berdasarkan Analisis SWOT Pada Perusahaan Tauco Cap Biruang Kabupaten Cianjur Jawa Barat. Program Manajemen Bisnis Koperasi, Fakultas Pertanian. Institut Pertanian Bogor. 